animals effectively even in remote areas and if repeated will eliminate the virus from wildlife. ${ }^{7}$ Furthermore, in such areas these campaigns rapidly become cost effective through the amounts of money saved by the veterinary and medical services.

The gene for the main protective protein of rabies virus has been introduced into the vaccine virus by genetic manipulation, and this can also act as an oral vaccine. ${ }^{89}$ The altered virus cannot revert back to virulent rabies virus, but it might accidentally infect species other than foxes. Thus improved vaccines and well developed techniques may one day make it possible to eradicate rabies from wildlife in Europe, though to do so will be costly and difficult. If, however, in due course the mainland of Europe becomes free of rabies this might give further protection to Britain (just as the successful vaccination against foot and mouth disease on the European mainland now protects our islands against the epidemics from which we used to suffer). At that stage it might be safe to drop the controls on animals from other parts of Europe as urged by the European Commission. It would, however, still be important to monitor the disease. Virus might enter the European Community countries from eastern Europe, the small risk from bat rabies might not be eliminated, and infected animals might still come from developing countries.
Until then, however, we must maintain our guard. But there seems no reason to suppose that traffic passing under the Channel cannot be controlled just as well as that travelling on its surface in ferries or small boats or above it in the air-in Britain we can expect our freedom from rabies to persist for the remaining decades of this century.

Director,

D A J TYRRELL

MRC Common Cold Unit,

Salisbury SP2 8BW

Consultant Physician and Science Lecturer,

K G NICHOLSON

Groby Hospital

Leicester LE3 9QE

1 World Health Organisation. Human rabies prophylaxis. Weekly Epidemiological Record 1989:97-8. (No 3.)

2 World Health Organisation. Rabies treatment. Weekly Epidemiological Record 1989:112-3. (No 5.) 3 Joint Committee on Vaccination and Immunisation. Immunization against infectious disease. London: HMSO, 1988

4 Immunization Practice Advisory Committee. MMWR 1984;33:15.

5 Lloyd HG. Wildlife rabies in Europe and the British situation. Trans $R$ Soc Trop Med Hyg 1976;70:179-87.

6 World Health Organisation Expert Committee on Rabies. Immunization of wildlife. Geneva: World Health Organisation, 1984. (Technical Report Series No 709.)

World Health Organisation. Fox rabies. Prophylaxis of fox rabies: a cost benefit study. Weekly Epidemiological Record 1989:189-92. (No 64.)

Epidemiological Record 1989:189-92. (No 64.)
Brochier BM, Languet B, Blancou J, et al. Use of recombinant vaccinia-rabies virus for oral Brochier BM, Languet B, Blancou J, et al. Use of recombinant vaccinia-rabies
vaccination of fox cubs (Vulpes vulpes L) against rabies. Vet Microbiol 1988;18:103-8. 9 Brochier BM. A field trial in Belgium to control fox rabies by oral immunization. Vet Rec
1988;123:618-21.

\title{
University hospitals and the NHS review
}

\section{A strong case for direct funding}

"Value for money" say the politicians when asked to explain the thinking behind the white paper on the NHS, but no one seems to have given enough thought to the extension of the white paper concepts to university medical education. The capitation funding of health authorities will require very substantial supplements for inner city factors, special services, tertiary referrals, and the service cost of undergraduate and postgraduate teaching and research if university hospitals and their medical schools are to survive; they stand or fall together. Meanwhile, or so it is said, hungry polytechnics wait in the wings to offer a cut price, no research, no nonsense medical education. But is a utility model sensible? And is it what the public really wants?

Why should medicine be taught as a university subject and not as a trade? After all, university education for medicine is mostly recent. In nineteenth century Britain the teaching hospitals and their own medical schools taught and the royal colleges and the apothecaries examined. Fierce indeed was the opposition from both profession and royal colleges when universities had the audacity to introduce degrees in medicine that were also a licence to practise. Yet as long ago as 1913 it was accepted that "the only justification for admitting technology of any kind into the range of university education is that the applied science involved does not consist in mere applications of science - inventions and discoveries which are stereotyped and can be learnt once and for all. Technology ... . means something quite different from this. It means the educational training which is...the necessary basis of the intelligent and progressive practice of the profession.... There is no profession in which this principle of education holds good more immediately, pressingly and continuously than in medicine."

What is or should be the distinctive contribution of the university to medical education? Medical teaching has always attempted to impart knowledge, skills, and attitudes, particu- larly the foundations of the clinical skills of communication and diagnosis - the human heart of medicine without which the rest makes less sense. Other aspects - investigation, treatment, prevention, family health, public health, information technology, and management - all need to be added in due course. This requires a more systematic and logical approach to understanding health and disease than is easily achieved with the random incidence of particular conditions in ward, clinic, and general practice.

The unique contribution of the university should be to "rouse the intelligence"- to stimulate, challenge, and inspire - and this is best done by those actively advancing their subjects in research. Abraham Flexner made just this point to the Royal Commission on Medical Education in London in 1913, explaining that confining education to today's techniques and horizons can never be sufficient for any doctor and that, paradoxically, the general practitioner is most in need of a lively intelligence. "The more isolated the doctor is apt to be, practising in the country or in a remote village, the more important that a medical training which thoroughly rouses his intelligence should send him forth with a momentum that may carry him further every day of his life." This is a task for universities, not for apprentice schools.

The current problems of funding and staffing in medical education began in 1974 when university hospitals ceased being directly funded by the Ministry of Health. This began a process of economic attrition as resources have failed to keep pace with demands. Yet at the same time the changes had the good result of forcing university hospitals to identify their service, teaching, and research with the surrounding community. A large part of health care in the inner cities now depends on these university hospitals. Focusing the service increment for teaching (SIFT) more specifically on service costs might make it possible for SIFT to be used to pay for special clinics arising directly from teaching in which little 
service but much teaching was done without cost to hospital or referring general practitioner. The problem is that other aspects of the university hospital's work previously funded in a general way out of SIFT would then be left unfunded unless additional resources were found.

What structure of funding would help to guarantee the future of medical education, research, and development in the NHS? How can we be sure to continue to attract many of the best brains into health care and use them to the full? Can we deny that while university hospitals surely must submit to strict managerial, medical, and educational audit (much of which they have themselves devised) their true success will never be measurable in commercial terms, that medical knowledge and development will be constrained in a market where cost effectiveness is the touchstone? Are we really prepared to see medical education and science jeopardised by the uncertain outcome of a market environment aimed at solving completely different problems?

There is no reason to doubt the sincerity and truth of $\mathrm{Mr}$ Clarke's statement on 10 July 1989 that "The comprehensive and high quality health service which will be needed to face the demands and challenges of tomorrow's world will depend crucially on the standard of medical education we provide and the range and quality of the nation's medical research programmes. Both are an intrinsic part of our commitment to the NHS" (speech to doctors in London).

We believe that the solution is to accept that it is in the national interest to have a small number of institutions whose special task it is to set the highest standards of care, to advance knowledge, and to inspire future doctors to excellence in a rapidly changing world, sending them out to every part of Britain once qualified with these models of care before them; and further, to accept that excellence is costly and must be funded, managed, and assessed in its own right but is at the same time a key component of care in the inner cities. This requires direct funding of the main university teaching hospitals by the Department of Health with a managerial mandate similar to that of the existing special health authorities but with the crucial difference that the undergraduate teaching hospitals continue to serve their locality as well as the country at large. Direct funding will not solve all the problems but it will greatly simplify the administrative process, stabilise the financial base, and allow time, energy, and imagination to be concentrated on the fundamental educational challenge, which has long been submerged in other pressures.

PETER RICHARDS

Dean,

St Mary's Hospital Medical School,

London W2 1PY

1 Roval Commission on University Education in London. Final report. London: HMSO, 1913.
Since Oppenheim introduced the term dystonia in 1911 it has had a rocky ride. ${ }^{1}$ The initial argument was whether dystonia was a neurological disease or was due to psychological distress. This seemed to be resolved when Herz resurrected the entity in $1944,{ }^{2}$ but instead the debate continued. Until the 1970 s most patients with dystonia were referred to psychiatrists in the belief that these curious motor disorders were an expression of an unhappy mind. Vigorous efforts over the past two decades have now, however, established that the various syndromes of dystonia are the result of abnormal brain function, usually in the basal ganglia. A cause for these movement disorders can be identified by modern investigation in about a quarter of cases; inheritance plays an important part in the remainder. Effective treatment can bé offered to most patients with this common disorder. ${ }^{34}$

\section{What is dystonia?}

Dystonia is a syndrome of sustained muscle contractions, frequently causing twisting and repetitive movements or abnormal postures. ${ }^{3}$ It can affect virtually any part of the body, and there are familiar names for dystonia at many different sites (box and figures 1-4). Typically, it starts in one part of the body as a focal dystonia. All dystonic movements and postures are worsened by attempts to move (action dystonia): to begin with they may appear only during a specific motor act, other movements being spared. If the syndrome is progressive (as is common in children but rare in adults) the initial action dystonia becomes apparent at rest and then spreads to affect other parts of the body (as segmental or multifocal dystonia); if progression continues dystonia may affect most or virtually all of the body (generalised dystonia).

Prolonged muscle contractions are the hallmark of dystonia; often they twist the body into characteristic postures. If continuous these spasms may cause constant twisted postures (except during deep stage three and four sleep and rapid eye movement sleep). If intermittent the spasms cause repetitive, often rhythmic jerks into dystonic postures - for example, the jerks of spasmodic torticollis. The shorter the spasms the more jerky or "myoclonic" is the dystonia. In addition, many patients with dystonia show true rhythmic tremors, either slow myorhythmias at about $3 \mathrm{~Hz}$ or faster tremors similar to those of benign essential tremor. Thus though dystonia is characterised by twisting spasms, it may also have additional myoclonic or tremulous components.

Age has a crucial but ill understood influence on the features of dystonia. The disease progresses to generalised or multifocal dystonia in some $60 \%$ of children (onset before the age of 13 years), in about $35 \%$ of adolescents (onset at 13-20), and in some $3 \%$ of adults (onset over the age of 20 ). Allied to this effect of age on the progression of dystonia is its effect on the site of onset. The legs are commonly affected first in children, less commonly in adolescents, and very rarely in adults. In summary, dystonia beginning in childhood usually 